\title{
Determinants of Cervical Cancer Screening among Jamaican Women
}

\author{
KA Barrett-Harrison, SR Priestley
}

\begin{abstract}
Objective: To assess the extent to which six sociodemographic variables and three lifestyle practices of women are associated with Pap smear testing, given that cervical cancer is the second leading cause of women's cancer mortality in Jamaica and that this cancer is preventable with the use of screening methods such as the Pap smear.

Methods: Secondary data from Jamaica's 2008 Reproductive Health Survey were utilized in the study. The sample consisted of 6123 women aged between 21 and 49 years who were sexually experienced. Logistic regression analysis was used to determine whether age, educational attainment, union status, area of residence, wealth quintile, parity, age of sexual initiation, number of lifetime sexual partners and smoking status could predict the likelihood of Pap smear screening among Jamaican women.

Results: Of the 6123 women, 79.1\% had participated in Pap smear screening. It was found that those who were younger, less educated, single, in visiting relationships, of lower wealth quintiles, had fewer children, an early age of sexual initiation, fewer lifetime sexual partners and who formerly smoked were less likely to undergo Pap smear screening.

Conclusion: Policies to increase cervical cancer screening should target women with the characteristics that make them less likely to be screened. Special attention should be directed to poor and uneducated women who are already burdened by their economic and social status. Invitation to screening and periodic small group educational sessions on cervical cancer at public health facilities should also be considered.
\end{abstract}

Keywords: Cervical cancer, lifestyle practices, Pap smear, sociodemographic factors

\section{Determinantes del cribado de cáncer cervical entre mujeres jamaiquinas}

\author{
KA Barrett-Harrison, SR Priestley
}

\begin{abstract}
RESUMEN
Objetivo: Evaluar hasta qué punto seis variables sociodemográficas y tres prácticas de estilo de vida de las mujeres, se asocian con las pruebas de Papanicolau, dado que el cáncer cervical es la segunda causa principal de mortalidad por cáncer entre las mujeres en Jamaica, a pesar de que este tipo de cáncer es prevenible con el uso de métodos de cribado como la citología vaginal.

Métodos: En el estudio se utilizaron datos secundarios de la Encuesta de Salud Reproductiva de Jamaica en 2008. La muestra estuvo formada por 6123 mujeres de entre 21 y 49 años de
\end{abstract}

From: Department of Sociology, Psychology and Social Work, Faculty of Social Sciences, The University of the West Indies, Mona, Jamaica, West Indies.

West Indian Med J 2018; 67 (1): 9
Correspondence: Dr SR Priestley, Department of Sociology, Psychology and Social Work, Faculty of Social Sciences, The University of the West Indies, Mona, Kingston 7, Jamaica, West Indies. Email: sharon.priestley@uwimona.edu.jm 
edad, que tuvieron experiencia sexual. Se utilizó un análisis de regresión logística para determinar si la edad, el nivel de educación, el estado de la unión, el área de residencia, el quintil de riqueza, la paridad, la edad de iniciación sexual, el número de parejas sexuales en su vida, y el estatus del hábito de fumar podrían predecir la probabilidad del cribado de la prueba de Papanicolau entre las mujeres jamaicanas.

Resultados: De las 6123 mujeres, el 79.1\% había participado en el cribado de la prueba citológica vaginal. Se encontró que las mujeres más jóvenes, menos educadas, solteras, con relaciones de visita, con quintiles de riqueza más bajos, menos hijos, temprana edad de iniciación sexual, menos parejas sexuales en su vida, y menos dadas a fumar, presentaban menor probabilidad de someterse a las pruebas de Papanicolau.

Conclusión: Las políticas encaminadas a aumentar el cribado del cáncer cervical, deben dirigirse a las mujeres con características que las hacen menos propensas a ser examinadas. Debe prestarse especial atención a las mujeres pobres e incultas, que ya están agobiadas por su estatus económico y social. También debe tenerse en cuenta la invitación a participar tanto en el cribado como en las sesiones educativas periódicas sobre el cáncer cervical, realizadas por grupos pequeños en los centros de salud pública.

Palabras clave: Cáncer cervical, prácticas de estilo de vida, citología vaginal, factores sociodemográficos

West Indian Med J 2018; 67 (1): 10

\section{INTRODUCTION}

According to the World Health Organization (WHO), cervical cancer is one of the deadliest forms of cancer affecting women, with 528000 women diagnosed and 266000 dying from this disease in 2012 (1). Cervical cancer ' $\mathrm{rob}[\mathrm{s}]$ women of life in their most productive years and frequently deprive[s] families of mothers and partners in mid-life' (2). In 2012, cervical cancer was the fourth leading cause of female cancer deaths and accounted for $7.5 \%$ of all female cancer deaths worldwide (3). In Jamaica, in 2012, it was the second leading cause of female cancer deaths and accounted for $13.2 \%$ of deaths among women from cancer (4). Recent data also showed that the mortality rate for cervical cancer in Jamaica was the second highest among seven Caribbean countries [5] (Table 1).

Table 1: Cervical cancer mortality rates in the Caribbean, 2012

\begin{tabular}{lc}
\hline Country & Mortality rate \\
\hline The Bahamas & 8.4 \\
Barbados & 10.8 \\
Cuba & 10.2 \\
Dominican Republic & 11.8 \\
Haiti & 11.1 \\
Jamaica & 13.2 \\
Trinidad and Tobago & 15.1 \\
\hline
\end{tabular}

Source: ICO Information Centre on HPV and Cancer (5)
There are a number of risk factors for cervical cancer. These include smoking, having multiple sexual partners, having a sexual partner with multiple partners or having a weakened immune system $(1,6,7)$. Women who have given birth to three or more children and women who have used oral contraceptives for five years or more have a greater risk of developing this disease $(6,7)$. Other risk factors are family history, a diagnosis of chlamydia or human papillomavirus (HPV) and engaging in sexual intercourse before 18 years of age (7).

Notwithstanding the risk factors, cervical cancer is a preventable disease $(1,8,9)$. According to the Centers for Disease Control and Prevention, United States of America (USA), two tests that help prevent cervical cancer are the Papanicolaou (Pap) smear and the HPV test (9). Visual inspection with acetic acid and the HPV vaccine are considered newer preventive measures not yet available in most low to middle income countries (2). These tests prevent cervical cancer since they identify precancerous changes, which, if left untreated, will progress to cervical cancer. Therefore, to guard against this disease, women should participate in these screening measures. The first cervical cancer screening guidelines with respect to the age at which screening should commence were developed in the 1980s. At that time, it was recommended that screening should commence at the age of 20 years for women who were not sexually active and before the age of 20 years for those sexually 
active (10). Over the years, the recommended age at which screening should commence has changed numerous times. However, the most recent recommendation indicated that women at average risk should commence screening three years after sexual initiation, or at the age of 18 years if they are sexually active, with tests every three years after two consecutive annual negative tests. Women with weakened immune systems or who are HIV-positive are encouraged to have annual checks ([11] and personal communication with the Director of Chronic Diseases and Injury Prevention in the Ministry of Health, Jamaica).

Although cervical cancer screening, and in particular the Pap smear, is a means of preventing the disease, Jamaican women tend to shy away from this procedure. This may be due to the stigma and fear of the implications of a cancer diagnosis. A review of cervical cancer screening (Pap smear) in the late 1990s among women aged 15 to 49 years in eight countries in Latin America and the Caribbean indicated that Jamaica had the lowest participation rate [Table 2] (3).

Table 2: Cervical cancer screening rates in Latin America and the Caribbean

\begin{tabular}{lc}
\hline Country (year) & $\begin{array}{c}\text { Percentage screened within the } \\
\text { last } 12 \text { months }\end{array}$ \\
\hline Costa Rica (1993) & 66.9 \\
Dominican Republic (1996) & 44.8 \\
Ecuador (1994) & 72.2 \\
Honduras (1996) & 55.4 \\
Jamaica (1997) & 15.3 \\
Nicaragua (1998) & 20.5 \\
Paraguay (1996) & 49.1 \\
Peru (1996) & 42.1 \\
\hline
\end{tabular}

Source: International Agency for Research on Cancer (3)

Several steps have been taken by both non-governmental organizations and the government to increase screening among Jamaican women considered to be most at risk. The Jamaica Cancer Society implemented a Mobile Pap Smear Screening programme in 2000 to reach women at their workplace or within their communities (12). In 2004, the Ministry of Health (MOH) launched a Cervical Cancer Programme targeting women between the ages of 25 and 45 years who had never had a Pap smear (13). The MOH indicated that this programme contributed to a decrease in the incidence of cervical cancer in Kingston and St Andrew, as the rate was 17.4 for the period 2003-07 compared to 25.2 for the period 1993-97 (13). This suggested that there was an increase in screening which allowed for precancerous changes to be detected and, as such, a decrease in the number of women diagnosed with the disease. Recent data from the $\mathrm{MOH}$ indicated that Pap smear screening at primary healthcare facilities had fluctuated over the last few years, increasing between 2005 and 2009 and declining between 2009 and 2010. This pattern repeated itself as screening increased between 2010 and 2012 and then declined between 2012 and 2015 (Figure). While the $\mathrm{MOH}$ did not provide an explanation for the decline, it may mean that fewer women participated in screening generally or that some women moved away from testing at public to private facilities.

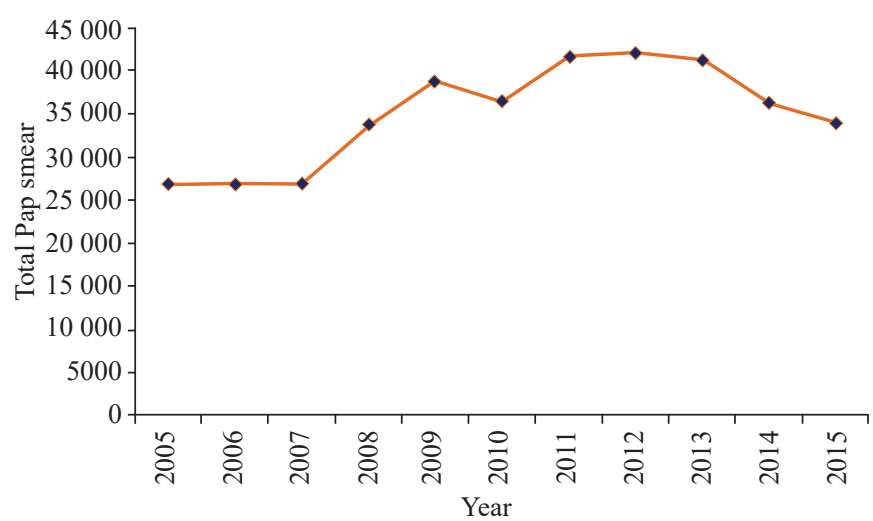

Figure: Pap smear screening at public primary healthcare facilities, 2005-15. Source: Ministry of Health, Jamaica

In the USA, the decline in mortality from cervical cancer between 1956 and 1996 was attributed to regular Pap smear testing among women (14). Since the decline in mortality rates in the 1990s in the USA, the mortality rates in the USA have remained consistently lower than those in other regions. For instance, in 2012, the mortality rate from cervical cancer in North America was 4.0 per 100000 women, compared to 10.6 in the Caribbean (15).

Previous studies have linked a number of factors with Pap smear testing. Sociodemographic variables such as age, educational attainment, union status, area of residence, wealth quintile and parity have been associated with Pap smear screening in studies conducted both locally and internationally. It has been reported that older age $(16,17)$, higher educational attainment $(16$, $18,19)$, being married $(17,20-22)$, residing in urban areas (23), higher wealth quintile (24) and having children (17) are associated with an increased likelihood of Pap smear screening.

Several lifestyle practices are concomitant with the extent of Pap smear testing. Older age of sexual initiation (25), multiple lifetime sexual partners (22) and being 
a former smoker $(26,27)$ have been associated with an increased likelihood of screening. Gu et al reported on the relationship between sexual history and Pap smear screening and indicated in their study that women who had their first sexual intercourse over the age of 21 years were more likely to be screened than women who had their first intercourse before that age (25). In a study by Louie et al, cervical cancer risk in developing countries was found to be twice as high in women whose age of sexual initiation was between 17 and 20 years as in women whose sexual debut was aged 21 years or above (28). The study found that these women at higher risk were being screened less. However, other studies have indicated that women with other risk factors for cervical cancer, such as multiple partners and being a former smoker, were more likely to participate in screening $(22,27)$.

Given the level of mortality from cervical cancer in Jamaica, the role of Pap smear testing in preventing cervical cancer, and the underutilization of Pap smear screening in Jamaica, this study was undertaken to uncover the characteristics of Jamaican women who were not utilizing this test and to highlight possible reasons for the gap in the uptake of screening tests to detect cervical cancer. The study specifically aimed to assess the impact of sociodemographic factors and lifestyle practices of women on their participation in Pap smear testing. The Health Belief Model, which looks at factors that determine whether people take action to prevent or screen for illnesses, was used as the framework to examine these relationships (29).

\section{SUBJECTS AND METHODS}

To investigate the sociodemographic factors and lifestyle practices associated with Pap smear testing in Jamaica, secondary data from Jamaica's 2008 Reproductive Health Survey (RHS) were utilized. The RHS is conducted periodically in Jamaica by the Statistical Institute of Jamaica and covers areas such as fertility, reproductive health and infant and child mortality. The RHS targets women aged 15-49 years and men aged 15-24 years. For the purpose of this study, the population of interest was sexually experienced women who were 21 years or older. Sexually experienced women were selected as most cases of cervical cancer are caused by HPV and people who are not sexually experienced are not at risk for HPV (30). Women aged 21 years or older were selected since the then most recent screening guidelines recommended that screening commence at that age. The total number of women included in the sample for analysis was 6123 .
The outcome variable of interest was "ever had a Pap smear', and there were two categories of predictor variables: sociodemographic factors and lifestyle practices. The sociodemographic variables were age, educational attainment, union status, area of residence, wealth quintile and parity, and the lifestyle practice variables were age of sexual initiation, number of lifetime sexual partners and smoking status. These sociodemographic variables were selected as they had been linked with Pap smear screening in both local and international studies. Therefore, this study explored whether the relationships identified in previous studies would be confirmed or refuted based on the RHS. Confirmation would strengthen existing theories as they relate to sociodemographic variables and Pap smear testing while refutation would provide alternative theories.

Those lifestyle practice variables were selected as they had been labelled as risk factors for cervical cancer by the WHO (1). Accordingly, the study explored whether women at risk for cervical cancer were undertaking screening to guard against the disease. The data were examined using bivariate and multivariate approaches and analysed with SPSS version 17.

The variables, age and age of sexual initiation, remained in their original format as continuous data. Also, wealth quintile remained unchanged as a categorical variable with five categories. The variable, educational attainment, had three categories: primary or lower, secondary and post-secondary. The first category consisted of women who had completed six years or less of schooling, and the second and third categories consisted of women who had completed 6-11 years of schooling and 12 or more years of schooling, respectively. Union status was also divided into three categories: married or common law, visiting partner or boyfriend and single. The variable, area of residence, had two categories: urban and rural. For the parity variable, women who indicated that they had three or more children were grouped into one category, and those who indicated none, one child or two children remained as they were. This was done since having three or more children had been recognized as a risk factor for cervical cancer $(6,7)$. Regarding the number of lifetime sexual partners, women who indicated that they had six or more partners were grouped in one category as research had indicated that women with six or more lifetime sexual partners were at risk for precancerous cervical abnormalities (30). The final variable, smoking status, had three categories: non-smoker, former smoker and current smoker. 
Binary logistic regression was used to test the degree to which age, educational attainment, union status, area of residence, wealth quintile, parity, age of sexual initiation, number of lifetime sexual partners, and cigarette smoking could predict Pap smear testing among women. The level of significance that was accepted was $p<0.05$. The variables were entered in the model in three blocks, using the forced entry method: block one for the sociodemographic variables, block two for the variables relating to lifestyle practices and block three for interaction effects. The interactions tested were age and parity, age and age of sexual initiation, and age and number of lifetime sexual partners. These interactions were selected as the age of women may have implications for variables such as parity, age of sexual initiation and number of lifetime sexual partners and their relationships to Pap smear screening. For instance, it is conceivable that older women would have more children than younger women or older women would have had more lifetime sexual partners than younger women. This can be attributed to the fact that older women have had a longer exposure to the risk of childbearing or sexual partners than younger women, by virtue of their age.

\section{RESULTS}

The majority of the respondents indicated that they had been screened for cervical cancer at some time in the past. Specifically, 79.1\% indicated that they had had a Pap smear previously, while $20.9 \%$ indicated that they had never had a Pap smear (Table 3).

Regarding age and Pap smear testing, it was revealed that screening was less common among women in the age group of 21-25 years than any other age group. As educational level progressed from primary to secondary to post-secondary, the percentage of women screened increased from $75.8 \%$ to $78.5 \%$ to $82.5 \%$. With respect to union status, the results indicated that Pap smear screening was most common among women in co-residential unions (82.0\%), compared with women in other relationship types (74.8\%) and single women $(79.0 \%)$. Screening was found to be more common among women in urban areas $(81.4 \%)$ than those in rural areas $(77.4 \%)$. With respect to wealth quintile, screening was most common among those in the highest quintile $(70.7 \%)$ and least common among those in the first and second quintiles (both at 64.6\%). Pap smear testing was least common among women who had never given birth $(57.5 \%)$, followed by women who had one child (79.6\%). It was noted that about $84 \%$ of the women who had given birth to two children indicated that they
Table 3: Distribution of study population by Pap smear screening status

\begin{tabular}{|c|c|c|c|c|}
\hline \multirow{3}{*}{ Variables } & \multicolumn{4}{|c|}{ Ever had a Pap smear } \\
\hline & \multicolumn{2}{|c|}{ Yes } & \multicolumn{2}{|c|}{ No } \\
\hline & $\mathbf{n}$ & $\%$ & n & $\%$ \\
\hline Total & 4825 & 79.1 & 1273 & 20.9 \\
\hline \multicolumn{5}{|l|}{ Age (years) } \\
\hline $21-24$ & 450 & 54.2 & 380 & 45.8 \\
\hline $25-29$ & 910 & 73.5 & 328 & 26.5 \\
\hline $30-34$ & 927 & 83.7 & 181 & 16.3 \\
\hline $35-39$ & 925 & 84.7 & 167 & 15.3 \\
\hline $40-44$ & 837 & 88.5 & 109 & 11.5 \\
\hline $45-49$ & 776 & 87.8 & 108 & 12.2 \\
\hline \multicolumn{5}{|l|}{ Educational attainment } \\
\hline Primary or lower & 169 & 75.8 & 54 & 24.2 \\
\hline Secondary & 3737 & 78.5 & 1024 & 21.5 \\
\hline Post-secondary & 913 & 82.5 & 193 & 17.5 \\
\hline \multicolumn{5}{|l|}{ Union status } \\
\hline Married/common law & 2543 & 82.0 & 560 & 18.0 \\
\hline $\begin{array}{l}\text { Visiting relationship/ } \\
\text { boyfriend }\end{array}$ & 1488 & 74.8 & 502 & 25.2 \\
\hline Single & 794 & 79.0 & 211 & 21.0 \\
\hline \multicolumn{5}{|l|}{ Area of residence } \\
\hline Urban & 2124 & 81.4 & 484 & 18.6 \\
\hline Rural & 2701 & 77.4 & 789 & 22.6 \\
\hline \multicolumn{5}{|l|}{ Wealth quintile } \\
\hline Lowest & 1288 & 64.6 & 706 & 35.4 \\
\hline Second & 1102 & 64.6 & 603 & 35.4 \\
\hline Middle & 1111 & 67.0 & 547 & 33.0 \\
\hline Fourth & 1091 & 66.5 & 549 & 33.5 \\
\hline Highest & 862 & 70.7 & 358 & 29.3 \\
\hline \multicolumn{5}{|l|}{ Parity } \\
\hline Never given birth & 470 & 57.5 & 348 & 42.5 \\
\hline One child & 1060 & 79.6 & 318 & 23.1 \\
\hline Two children & 1224 & 84.5 & 224 & 15.5 \\
\hline Three or more children & 2027 & 84.4 & 383 & 15.6 \\
\hline \multicolumn{5}{|l|}{ Age of sexual initiation (years) } \\
\hline $10-15$ & 1294 & 77.9 & 368 & 22.1 \\
\hline $16-19$ & 2894 & 79.2 & 762 & 20.8 \\
\hline 20 or over & 637 & 81.7 & 143 & 18.3 \\
\hline \multicolumn{5}{|l|}{ Lifetime sexual partners } \\
\hline One & 750 & 74.3 & 259 & 25.7 \\
\hline Two & 1056 & 77.4 & 309 & 22.6 \\
\hline Three & 1063 & 79.4 & 276 & 20.6 \\
\hline Four & 684 & 82.0 & 150 & 18.0 \\
\hline Five & 462 & 80.5 & 112 & 19.5 \\
\hline Six or more & 564 & 82.3 & 121 & 17.7 \\
\hline \multicolumn{5}{|l|}{ Smoking status } \\
\hline Non-smoker & 4459 & 79.3 & 1161 & 20.7 \\
\hline Former smoker & 136 & 76.8 & 41 & 23.2 \\
\hline Current smoker & 224 & 76.7 & 68 & 23.3 \\
\hline
\end{tabular}


had received a Pap smear; similar results were noted for women who had given birth to three or more children.

As it relates to age of sexual initiation and Pap smear testing, the results indicated that as the age of sexual initiation increased, the percentage of women who had received a Pap smear also increased. Pap smear testing was least common among women who reported one lifetime sexual partner $(74.3 \%)$ and most common among women who indicated that they had had six or more lifetime sexual partners $(82.3 \%)$. With respect to smoking, $79.3 \%$ of non-smokers indicated that they had received a Pap smear while $76.8 \%$ of former smokers and $76.7 \%$ of current smokers indicated that they had received a Pap smear.

All the sociodemographic variables emerged as significant predictors of Pap smear testing in blocks one and two in the regression model. Increasing age, higher educational attainment, being in a co-residential union, residing in urban areas, higher wealth quintile and having more children were associated with a higher uptake of Pap smear screening among Jamaican women. In block three, when the interaction effects were entered, age lost its significance as an individual predictor. However, the interaction between age and parity was a significant predictor of Pap smear testing (Table 4). While age of sexual initiation was not a significant predictor of Pap smear testing, when combined with age of women, it became a significant predictor of screening. Area of residence also lost its significance as a predictor of Pap smear testing in block three.

Table 4 shows that with respect to educational attainment, women with post-secondary education were twice more likely (odds ratio $=2.268$ ) to undertake Pap smear testing than women with primary or lower level of education, and women with secondary education were one-and-a-half times more likely (odds ratio $=1.539$ ). We also found that women in non-residential unions had lower odds of undertaking Pap smear screening than women in other relationship types (odds ratio $=0.825$ ) or single women (odds ratio $=0.770$ ). As wealth quintile increased, the odds of Pap smear testing also increased. Specifically, women in the second, middle, fourth and highest quintiles were about one to three times more likely to undergo screening compared with women in the lowest quintile (odds ratios of 1.270, 1.532, 1.689 and 2.666, respectively).

The relationship between lifestyle practices and Pap smear screening was not as consistent as the relationship between the demographic background variables and Pap smear screening. In fact, being a former smoker
Table 4: Logistic regression model predicting Pap smear testing status

\begin{tabular}{|c|c|c|}
\hline Variables & $\begin{array}{l}\text { Odds } \\
\text { ratios }\end{array}$ & $\begin{array}{c}95 \% \\
\text { confidence } \\
\text { intervals }\end{array}$ \\
\hline Age & 1.026 & $0.951,1.107$ \\
\hline \multicolumn{3}{|l|}{ Educational attainment } \\
\hline Primary or lower & Reference & \\
\hline Secondary & 1.539 & $1.092,2.167 *$ \\
\hline Post-secondary & 2.268 & $1.532,3.360^{*}$ \\
\hline \multicolumn{3}{|l|}{ Union status } \\
\hline Married/common law & Reference & \\
\hline Visiting relationship/boyfriend & 0.825 & $0.707,0.963 *$ \\
\hline Single & 0.770 & $0.634,0.936$ \\
\hline \multicolumn{3}{|l|}{ Area of residence } \\
\hline Urban & 1.146 & $0.991,1.325$ \\
\hline Rural & Reference & \\
\hline \multicolumn{3}{|l|}{ Wealth quintile } \\
\hline Lowest & Reference & \\
\hline Second & 1.270 & $1.050,1.536^{*}$ \\
\hline Middle & 1.532 & $1.248,1.882 *$ \\
\hline Fourth & 1.689 & $1.356,2.105^{*}$ \\
\hline Highest & 2.666 & $2.018,3.522 *$ \\
\hline Parity & 4.222 & $3.145,5.666^{*}$ \\
\hline Age of sexual initiation (years) & 0.879 & $0.770,1.004$ \\
\hline Number of lifetime sexual partners & 0.901 & $0.744,1.091$ \\
\hline \multicolumn{3}{|l|}{ Smoking status } \\
\hline Non-smoker & Reference & \\
\hline Current smoker & 0.853 & $0.623,1.166$ \\
\hline Former smoker & 0.671 & $0.452,0.997^{*}$ \\
\hline Age by parity & 0.967 & $0.958,0.975^{*}$ \\
\hline Age by age of sexual initiation & 1.004 & $1.001,1.008^{*}$ \\
\hline Age by number of lifetime sexual partners & 1.006 & $1.000,1.012$ \\
\hline
\end{tabular}

*Significant at alpha 0.05

was the only significant predictor of Pap smear testing in the final model. The odds ratio of 0.671 indicates that the likelihood of screening among former smokers was lower than the likelihood of screening among nonsmokers. No statistically significant difference in the likelihood of screening existed between current smokers and non-smokers.

\section{DISCUSSION}

Overall, the increased likelihood of participating in Pap smear testing among Jamaican women was associated with having secondary or post-secondary education, being married, higher wealth quintile, having more children and being a non-smoker. The strongest predictors 
of screening among Jamaican women were educational attainment and parity while the weakest predictors were union status and former smoker status. These findings are consistent with previous studies $(16-18,20)$. While age did not emerge as a significant predictor of Pap smear screening in Jamaican women in the final model in the current study, it had been linked with screening in other Jamaican studies $(16,17)$. The difference in findings may be explained by the regression models used. For instance, the other studies did not test the interaction between age and other variables in their models.

The finding that the odds of Pap smear testing was lower for women with primary education than for women with secondary or higher education was also consistent with those in previous studies $(18,31)$. According to Feinstein et al, increasing educational level was associated with increasing utilization of preventative healthcare services (19). Further, it was pointed out that in countries such as the USA, Canada and Australia, women with higher education were more likely to undergo regular cervical cancer screening (19). Women with the lowest educational level are the least likely to participate in Pap smear screening.

There are a number of explanations for the finding that married women or women living with partners were more likely to participate in Pap smear testing than single women or women in visiting relationships. Firstly, male partners may provide support for positive health-seeking behaviour and thus may encourage their female partners to undergo testing. Bingham et al indicated that the difference in the screening behaviours of married and unmarried women may be attributed to the emotional and social support that the former group receives from their husbands or partners (32). Secondly, women who are single may not be sexually active and therefore may not see the need for Pap smear testing. Thirdly, single women may also be single parents and as such may have less time and fewer financial resources to access preventative healthcare such as Pap smear screening.

Our finding that wealth quintile was significantly associated with screening reflects women's skewed access to screening tests and other diagnostic and treatment services and warrants our concern. That women in the highest wealth quintile were about three times more likely to have had a Pap smear compared with the poorest women means that the utilization of screening services to maintain women's health was still largely dependent on their socio-economic status. The affordability of screening and other diagnostic tests will need to be addressed in an effort to reach those sexually active women who have never had a Pap smear in order to initiate earlier detection and control of this type of cancer. This was articulated in recent literature that reviewed the state of women's cancers globally $(2,10)$.

Parity has also been linked to cervical cancer screening. According to the Centers for Disease Control and Prevention and Cancer Treatment Centers of America, women who had given birth to three or more children had a greater risk of developing cervical cancer than nulliparous women or women with one or two children $(6,7)$. The study showed that increasing parity was associated with increasing likelihood of Pap smear testing. Ncube et al argued that women with children were more likely to participate in Pap smear screening compared with nulliparous women since the former group would have greater opportunities for screening simply by attending maternal and health clinics (17). For instance, pregnant women are expected to attend scheduled healthcare visits leading up to the birth of their children. With these visits, such women have more opportunities to discuss reproductive health-related matters compared to women who have never been pregnant and therefore are not expected to have attended scheduled prenatal healthcare visits. Other studies have indicated that women who visited their healthcare providers regularly were more likely to participate in Pap smear screening than women who did not visit regularly $(16,17)$.

In the present study, the interaction between a woman's age and her age of sexual initiation was found to be a significant predictor of screening. This suggests that age of sexual initiation had implications for Pap smear screening only when the age of the woman was factored in. However, the number of lifetime sexual partners was not found to be a significant predictor of screening on its own or when combined with age. This reflects the limited use of this variable in predicting screening among Jamaican women, although it has been found to be useful in Tanzania (22). It was also noted that urban residence was not a significant predictor of screening when other variables were controlled for. The wide differences between women in urban and in rural areas in access to screening may actually be accounted for by differences in their levels of poverty.

The results of the study indicated that there was no statistically significant difference in the rates of Pap smear screening among current smokers and non-smokers. However, this may be due to the small number of smokers in the sample. In addition, it was depicted that former smokers were less likely to undergo screening than non-smokers. These findings warrant concern, 
given that smoking increases cervical cancer risk $(6,7$, $33,34)$. The latter finding also differed from that reported in previous studies in the USA and Switzerland. The results from these studies indicated that former smokers were more likely to participate in Pap smear screening than non-smokers $(26,27)$.

This study highlighted some of the characteristics of women who were unlikely to undergo Pap smear screening - women who were poor and uneducated and had smaller family sizes. Given that cervical cancer is the second leading cause of female cancer mortality in Jamaica, we are encouraged that the $\mathrm{MOH}$ has introduced the HPV vaccine to girls aged 9 to 14 years in school in order to provide $90-100 \%$ protection against HPV types 16 and 18 which are responsible for most HPV-caused cancers. Yet, more needs to be done to increase the screening rate as it facilitates early detection, reduces risk and places a priority on prevention rather than treatment. We recommend that the $\mathrm{MOH}$ undertake an assessment of the feasibility of sending cervical cancer screening invitation letters. Invitation letters for Pap smear testing have successfully improved cervical cancer screening rates in developed countries such as Canada (35). Specifically, in a randomized trial design involving over 30000 women, those sent invitation letters were twice more likely to have had a Pap smear in the ensuing six months than those who did not receive invitation letters (35).

Secondly, there should be more sustained and extensive small group educational sessions at public health facilities (such as clinics and health centres) on cervical cancer and Pap smear screening. Partnerships may be forged with civil society (non-governmental and non-business organizations, along with individuals) to implement this strategy and provide support to healthcare providers so that women who are the least likely to undergo screening are empowered to do so.

\section{REFERENCES}

1. World Health Organization. New guidance for the prevention and control of cervical cancer [Internet]. Geneva, Switzerland; 2015 [cited 2015 Nov 11]. Available from: www.who.int/reproductivehealth/topics/en.

2. Ginsburg O, Bray F, Coleman MP, Vanderpuye V, Eniu A, Kotha SR et al. The global burden of women's cancers: a grand challenge in global health. Lancet 2017; 389: 847-60.

3. International Agency for Research on Cancer. IARC handbooks of cancer prevention. Vol 10. France: IARC Press; 2005.

4. Bruni L, Barrionuevo-Rosas L, Albero G, Serrano B, Mena M, Gómez $\mathrm{D}$ et al. ICO/IARC Information Centre on HPV and Cancer (HPV Information Centre). Human papillomavirus and related diseases in Jamaica. Summary report December 2015 [cited 2016 Feb 17].

5. Bruni L, Barrionuevo-Rosas L, Albero G, Serrano B, Mena M, Gómez $\mathrm{D}$ et al. ICO/IARC Information Centre on HPV and Cancer (HPV Information Centre). Human papillomavirus and related diseases report in Americas [Internet]. Barcelona, Spain; 2015 [cited 2016 Oct 11]. Available from: www.hpvcentre.net/statistics/reports/XMX.pdf.

6. Centers for Disease Control and Prevention. What are the risk factors for cervical cancer? [Internet]. Atlanta, GA: Centers for Disease Control and Prevention; 2014 [cited 2016 Feb 3]. Available from: www.cdc.gov/ cancer/cervical/basic_info/risk_factors.htm.

7. Cancer Treatment Centers of America. Cervical cancer risk factors [Internet]. Boca Raton, Florida: Cancer Treatment Centers of America; 2015 [cited 2016 Feb 3]. Available from: www.cancercenter.com/ cervical-cancer/risk-factors.

8. Berer M. Editorial: reproductive cancers: high burden of disease, low level of priority. Reproductive Health Matters 2008; 16: 4-8.

9. Centers for Disease Control and Prevention. What can I do to reduce my risk of cervical cancer? [Internet]. Atlanta, GA: Centers for Disease Control and Prevention; 2014 [cited 2015 Nov 12]. Available from: www.cdc.gov/cancer/cervical/basic_info/prevention.htm.

10. American Cancer Society. History of ACS recommendations for early detection of cancer in people without symptoms [Internet]. Atlanta, GA; 2014 [cited 2016 Dec 15]. Available from: www. cancer.org/healthy/findcancerearly/cancerscreeningguidelines/ chronological-history-of-acs-recommendations.

11. Bruni L, Barrionuevo-Rosas L, Albero G, Serrano B, Mena M, Gómez $\mathrm{D}$ et al. ICO/IARC Information Centre on HPV and Cancer (HPV Information Centre). Human papillomavirus and related diseases in Jamaica. Summary report July 27, 2017. Available from: www.hpvcentre.net/statistics/reports/JAM.pdf.

12. Jamaica Cancer Society. Our services: mobile Pap smear screening [Internet]. Kingston, Jamaica: Jamaica Cancer Society; 2015 [cited 2015 Nov 13]. Available from: http://jamaicacancersociety.org/607-2.

13. Ministry of Health, Jamaica. Strategic plan and action plan for the prevention and control of cancer in Jamaica [Internet]. Kingston, Jamaica: Ministry of Health; 2013 [cited 2016 Feb 5]. Available from: http:// moh.gov.jm/wp-content/uploads/2015/12/NATIONAL-CANCERSTRATEGIC-AND-ACTION-PLAN-JAMAICA.pdf.

14. Centers for Disease Control and Prevention. Cervical cancer statistics [Internet]. Atlanta, GA; 2016 [cited 2016 Oct 12]. Available from: www. cdc.gov/cancer/cervical/statistics.

15. Bruni L, Barrionuevo-Rosas L, Albero G, Serrano B, Mena M, Gómez $\mathrm{D}$ et al. ICO/IARC Information Centre on HPV and Cancer (HPV Information Centre). Human papillomavirus and related diseases report in the world [Internet]. Barcelona, Spain; 2015 [cited 2016 Oct 12]. Available from: www.hpvcentre.net/statistics/reports/XWX.pdf.

16. Bessler P, Aung M, Jolly P. Factors affecting uptake of cervical cancer screening among clinic attendees in Trelawny, Jamaica. Cancer Control 2007; 14: 396-404.

17. Ncube B, Bey A, Knight J, Bessler P, Jolly P. Factors associated with the uptake of cervical cancer screening among women in Portland, Jamaica. N Am J Med Sci 2015; 7: 104-13.

18. Akinyemiju TF. Socio-economic and health access determinants of breast and cervical cancer screening in low-income countries: analysis of the World Health Survey. PLoS One 2012; 7: e48834.

19. Feinstein L, Sabates R, Anderson T, Sorhaindo A, Hammond C. What are the effects of education on health? Paper presented at: The International Symposium on Measuring the Social Outcomes of Learning, March 23-4, 2006, Copenhagen, Denmark [cited 2016 Mar 1]. Available from: www.oecd.org/edu/innovation-education/37425753.pdf.

20. Martins L, Valente J, Thuler L. Factors related to inadequate cervical cancer screening in two Brazilian state capitals. Rev. Saúde Pública 2009; 43: 318-25.

21. Arrossi S, Ramos S, Paolino M, Sankaranarayanan R. Social inequality in Pap smear coverage: identifying under-users of cervical cancer screening in Argentina. Reprod Health Matters 2008; 16: 50-8.

22. Kileo N, Michael D, Neke N, Moshiro C. Utilization of cervical cancer screening services and its associated factors among primary school teachers in Ilala Municipality, Dar es Salaam, Tanzania. BMC Health Serv Res 2015; 15: 1-9.

23. Wang B, He M, Chao A, Engelgau M, Saraiya M, Wang L et al. Cervical cancer screening among adult women in China, 2010. Oncologist 2015; 20: $627-34$. 
24. Soneji S, Fukui N. Socioeconomic determinants of cervical cancer screening in Latin America. Rev Panam Salud Publica 2013; 33: 174-82.

25. Gu C, Chan C, Twinn S. How sexual history and knowledge of cervical cancer and screening influence Chinese women's screening behavior in Mainland China. Cancer Nurs 2010; 33: 445-53.

26. Richard A, Rohrmann S, Schmid S, Tirri B, Huang D, Guth U et al. Lifestyle and health-related predictors of cervical cancer screening attendance in a Swiss population-based study. Cancer Epidemiol 2015; 39: $870-6$.

27. Vander M, Howren B, Cai X. Use of routine clinical preventive services among daily smokers, non-daily smokers, former smokers, and neversmokers. Nicotine Tob Res 2012; 14: 123-30.

28. Louie KS, Sanjose S, Diaz M, Castellsague X, Herrero R, Meijer CJ et al. Early age at first sexual intercourse and early pregnancy are risk factors for cervical cancer in developing countries. Br J Cancer 2009; 100: $1191-7$.

29. Janz N, Becker M. The health belief model: a decade later. Health Educ Q 1984; 11: 1-47.
30. National Cancer Institute. HPV and cancer [Internet]. Bethesda, MD: National Cancer Institute; 2005 [cited 2016 Apr 12]. Available from: www.cancer.gov/about-cancer/causes-prevention/risk/infectious -agents/hpv-fact-sheet.

31. Peterson NB, Murff HJ, Cui Y, Hargreaves M, Fowke JH. Papanicolaou testing among women in the southern United States. J Womens Health (Larchmt) 2008; 17: 939-46.

32. Bingham A, Bishop A, Coffey P, Winkler J, Bradley J, Dzuba L et al. Factors affecting utilization of cervical cancer prevention services in low-resource settings. Salud Publica Mex 2003; 45: 408-16.

33. Meyers C, Alam S, Conway M. How does tobacco smoke contribute to cervical carcinogenesis? J Virol 2008; 82: 6084-6.

34. Fonseca-Moutiho J. Smoking and cervical cancer. ISRN Obstet and Gynecol 2011; 2011: article ID 847684.

35. Decker KM, Turner D, Demers AA, Martens PJ, Lambert P, Chateau D. Evaluating the effectiveness of cervical cancer screening invitation letters. J Womens Health (Larchmt) 2013; 22: 687-93. 